\title{
Research on Green Comprehensive Evaluation Model of Urban Distribution Network Electric Energy Based on CRITIC-Order Relation Analysis Method Combination Weighting
}

\author{
Yang $\mathrm{Du}^{1, \mathrm{a}}$, Xingang Yang ${ }^{1}, \mathrm{Su}_{\mathrm{Lei}}{ }^{1}$, Lingyu $\mathrm{Guo}^{1}$, Boyuan $\mathrm{Cao}^{1}$ \\ ${ }^{1}$ State Grid Shanghai Municipal Electric Power Company, Shanghai, 200001, China
}

\begin{abstract}
The green evaluation of urban power distribution network is the main reference basis for power grid transformation and upgrading. Based on this, this article constructs a comprehensive evaluation index system from the four dimensions of power supply side, consumer side, platform area and related policies; To comprehensively consider the difference and relevance of indicators, this paper adopts the order relationship analysis method and the CRITIC weighting method for subjective and objective combination weighting, and uses linear weighting to score indicators; Finally, combining the four evaluation dimensions to analyze the application approach of the comprehensive evaluation model to verify the practicability of the model.
\end{abstract}

\section{Introduction}

Under the background of ecological civilization construction and energy revolution strategy, promoting clean transformation has become the general trend of energy development. As the pivot of energy transformation, power grid connects the upstream and downstream of the power industry, and its clean development function will be extended by the power system to the whole energy system. With the improvement of clean development level of power grid, the rational evaluation of power green index of power distribution network can comprehensively reflect the clean level of power production, transportation, distribution and consumption process, which is conducive to improve efficiency, save resources, reduce waste discharge and promote the coordinated development of ecological health. Therefore, combining with the connotation of green circular economy, it is particularly important to objectively and accurately evaluate the green development level of electric energy in urban distribution network.

Some researches have been carried out on the safe operation of distribution network and the evaluation of low-carbon development. In terms of safe operation of the distribution network, reference [1] proposed a comprehensive power quality evaluation method based on combination weight and improved grey correlation analysis, which accurately evaluates power quality through optimization of index weight and reflects the safe operation level of power grid; reference [2] proposed a comprehensive evaluation method of CRITIC-TOPSIS, which makes full use of the original data information and considers the differences and correlations between the indicators for power quality evaluation; reference [3] analyzed the main points of the comprehensive evaluation of the production and operation safety of the urban distribution network in combination with the evaluation index system. Aiming at the low-carbon development of the distribution network, reference [4] considered the low-carbon benefits of the distribution network, and proposed a low-carbon operation optimization method for the distribution network based on distributed generation system configuration, resource planning, and optimal dispatching strategies; reference [5] analyzed the formation mechanism and characteristics of low-carbon benefits of power grids, and established a standardized low-carbon benefit evaluation model of power grids; reference [6] focused on the three dimensions of power supply, power distribution, and electricity consumption to constructed the evaluation index system of low carbon level of distribution network from four angles: low carbon power supply, low loss network, peak load shifting and terminal emission reduction. On the one hand, the above studies have optimized the safe operation of the distribution network, the weighting of low-carbon development indicators, and the evaluation methods. However, the impact of clean energy supply and consumption based on safe operation of power grid was not comprehensively considered when constructing the indicator system; On the other hand, the research on the evaluation model of the distribution network is mainly carried out from a single perspective, and there are few studies on the comprehensive evaluation of the green development level of the distribution network from multiple dimensions.

Based on the existing comprehensive evaluation research of distribution network, this paper focuses on the construction of the green evaluation index system

$\overline{{ }^{a} \text { Corresponding author: 1269096510@qq.com }}$ 
and evaluation method of power distribution network. First, selecting reasonable evaluation indicators around the power green elements of the distribution network and building a green evaluation index system for the urban power distribution network from the four dimensions of the power source side, the consumer side, the safe operation of the station area, and the level of policy support, which reflects the green power supply level and clean power consumption level of urban distribution network, and provides the development red line for new energy access and electric power replacement level of distribution network on the premise of safe operation of distribution network area. At the same time, the incentive effect of the policy on the supply side, consumption side and operation side of the distribution network is quantified. Based on the sequence relationship analysis method and the CRITIC weighting method carries out subjective and objective weighting, and the geometric average method is used to obtain the comprehensive weight; Finally, the application method of the green comprehensive evaluation model for electric energy is proposed.

\section{Construction of Green Index System for Electric Energy in Distribution Network}

\subsection{Principle of index extraction}

Research on the construction of a green indicator system for electric energy can comprehensively reflect the overall level of clean power development, and intuitively reflect the level and trend of "green power" development and utilization. The index extraction in this paper follows the following principles:

(1) Combination of completeness and pertinence. The selected indicators should not only reflect the various elements that affect the green development of the distribution network as fully as possible, but also reflect the operating characteristics of the distribution network.

(2) Combination of science and accessibility. The relevance of evaluation indicators should be as small as possible, and ensure that there is no redundancy [6].

\subsection{Construction of the index system}

Combining with the power transmission process, the urban distribution network is divided into three parts: power supply, station area and electricity consumption. Under the promotion of relevant energy policies, the distribution network can achieve clean development in the following ways:

(1) The power side minimizes the negative impact on the environment by expanding the proportion of new energy installed, changing the power structure, and improving power generation technology to minimize pollutant emissions, improve energy utilization efficiency, and so on.

(2) On the load side, the implementation of demandside response and electric energy substitution can increase the absorption space of new energy, which is conducive to optimizing the energy consumption structure, ensuring the direction of green development and realizing the green development of regional economy.

(3) The safe operation of the power grid is the premise and prerequisite for the green development of the supply side and the demand side. In the process of promoting the green development of the power distribution network, the priority of safety and the importance of a veto should be reflected, so as to determine the sustainability and popularization of the current green development of the supply side and the demand side.

(4) Policy incentives can change the pattern of interests of the supply and demand sides, improve the dispatch flexibility of new energy generation and the degree of user demand response, so as to improve the level of new energy consumption and achieve green development.

Based on the above analysis of the factors affecting the green development of the urban distribution network, four first-level evaluation indicators are extracted such as energy supply environmentally and friendly, lowcarbon and energy-saving energy consumption, safety and stability in the station area, and the level of energy policy support, which are used as the basis of urban distribution network energy green comprehensive evaluation index system architecture. Specific include:

(1) On the supply side, the impact of installed capacity of clean energy, on-grid electricity, and supplydemand relationship changes on the security of power grid is considered. On this basis to reflect the degree of green supply of energy on the supply side. Based on "Electricity comes from afar" and "Electricity comes from around", taking the main network and the distribution network of the park as the object to extract the indexes. The meanings and calculation methods of specific indicators are shown in Table 1:

Table 1. Calculation method of green development index of electric energy on the supply side

\begin{tabular}{|c|c|c|c|c|}
\hline \multicolumn{2}{|c|}{ Index Level } & $\begin{array}{c}\text { Index Definition and } \\
\text { Calculation Method }\end{array}$ & Unit & Index Significance \\
\hline \multirow{3}{*}{$\begin{array}{c}\text { Main } \\
\text { Network }\end{array}$} & $\begin{array}{c}\text { The proportion } \\
\text { of electricity } \\
\text { generated by } \\
\text { clean energy }\end{array}$ & $\begin{array}{c}\text { The proportion of } \\
\text { electricity generated by } \\
\text { various types of clean } \\
\text { energy in total } \\
\text { electricity generation }\end{array}$ & $\%$ & $\begin{array}{c}\text { Reflecting the regional power generation structure and } \\
\text { the development level of all kinds of clean energy }\end{array}$ \\
\cline { 2 - 6 } & $\begin{array}{c}\text { The proportion } \\
\text { of clean }\end{array}$ & $\begin{array}{c}\text { The proportion of clean } \\
\text { electric that connected }\end{array}$ & $\%$ & $\begin{array}{c}\text { Reflecting the green development degree and clean } \\
\text { energy consumption level of power transmission and }\end{array}$ \\
\hline
\end{tabular}




\begin{tabular}{|c|c|c|c|c|}
\hline & $\begin{array}{l}\text { electricity that } \\
\text { connected to } \\
\text { grid } \\
\end{array}$ & $\begin{array}{l}\text { to the gird in total on- } \\
\text { grid electricity }\end{array}$ & & distribution side \\
\hline & $\begin{array}{l}\text { The proportion } \\
\text { of pure } \\
\text { purchased } \\
\text { electricity }\end{array}$ & $\begin{array}{l}\text { The proportion of } \\
\text { external power supply } \\
\text { in the total area } \\
\text { electricity }\end{array}$ & $\%$ & $\begin{array}{l}\text { Investigating the development of inter-regional power } \\
\text { transmission and reflecting the cleanliness of external } \\
\text { power through the comparison of the proportion of } \\
\text { thermal power and clean power }\end{array}$ \\
\hline & $\begin{array}{l}\text { The proportion } \\
\text { of high } \\
\text { efficiency units } \\
\text { installed in } \\
\text { thermal power } \\
\text { plants }\end{array}$ & $\begin{array}{l}\text { The proportion of the } \\
\text { installed capacity of } \\
\text { high energy efficiency } \\
\text { units in the total } \\
\text { installed capacity of } \\
\text { thermal power plants in } \\
\text { the region }\end{array}$ & $\%$ & $\begin{array}{c}\text { Reflecting the level of thermal power plant cleaning } \\
\text { optimization }\end{array}$ \\
\hline \multirow{4}{*}{ Park } & $\begin{array}{l}\text { The proportion } \\
\text { of installed } \\
\text { photovoltaic } \\
\text { capacity } \\
\end{array}$ & \multirow{4}{*}{$\begin{array}{l}\text { The proportion of } \\
\text { installed capacity of } \\
\text { various types of power } \\
\text { sources in the total } \\
\text { installed capacity of the } \\
\text { park }\end{array}$} & \multirow{4}{*}{$\%$} & \multirow{4}{*}{$\begin{array}{l}\text { Reflecting the clean power supply level of the distribution } \\
\text { network in the park }\end{array}$} \\
\hline & $\begin{array}{l}\text { The proportion } \\
\text { of installed wind } \\
\text { power capacity }\end{array}$ & & & \\
\hline & $\begin{array}{l}\text { The proportion } \\
\text { of installed } \\
\text { capacity of } \\
\text { garbage power } \\
\text { plant } \\
\end{array}$ & & & \\
\hline & $\begin{array}{l}\text { The proportion } \\
\text { of installed } \\
\text { capacity of } \\
\text { cogeneration }\end{array}$ & & & \\
\hline
\end{tabular}

(2) Consumer-side user types mainly include large industrial users, general industrial and commercial users, residential users, and industrial park users. For considering data availability and reference value, industrial park users are selected for index extraction. The meanings and calculation methods of specific indicators are shown in Table 2:

Table 2 Calculation method of green development index of electric energy on the demand side

\begin{tabular}{|c|c|c|c|}
\hline Index Level & $\begin{array}{l}\text { Index Definition and } \\
\text { Calculation Method }\end{array}$ & Unit & Index Significance \\
\hline $\begin{array}{l}\text { Controllable load ratio of } \\
\text { smart power consumption }\end{array}$ & $\begin{array}{l}\text { The proportion of the } \\
\text { controllable load to the } \\
\text { total load }\end{array}$ & $\%$ & $\begin{array}{l}\text { Reflecting the adjustable level of } \\
\text { consumption side power load }\end{array}$ \\
\hline $\begin{array}{l}\text { Utilization rate of electrical } \\
\text { energy }\end{array}$ & $\begin{array}{l}\text { The proportion of the } \\
\text { energy output that can } \\
\text { be used efficiently to } \\
\text { the electrical energy } \\
\text { input }\end{array}$ & $\%$ & $\begin{array}{l}\text { Reflecting the effect of energy saving } \\
\text { and emission reduction in users' } \\
\text { production and life }\end{array}$ \\
\hline $\begin{array}{l}\text { Peak to valley ratio of } \\
\text { energy }\end{array}$ & \multicolumn{2}{|c|}{$\begin{array}{l}\text { The proportion of peak load to } \\
\text { valley load }\end{array}$} & $\begin{array}{l}\text { Reflecting the efficiency of peak } \\
\text { clipping and valley filling caused by } \\
\text { energy conversion }\end{array}$ \\
\hline $\begin{array}{l}\text { Development level of } \\
\text { replacing oil with electricity }\end{array}$ & $\begin{array}{l}\text { The proportion of } \\
\text { electric vehicle } \\
\text { charging pile capacity } \\
\text { to substation capacity } \\
\text { and vehicle-pile ratio }\end{array}$ & $\%$ & \multirow{2}{*}{$\begin{array}{l}\text { Reflecting the park clean energy, } \\
\text { promotion and application of electric } \\
\text { energy replacement level }\end{array}$} \\
\hline $\begin{array}{l}\text { Development level of } \\
\text { replacing coal with } \\
\text { electrcity }\end{array}$ & $\begin{array}{l}\text { The proportion of } \\
\text { electric boiler, electric } \\
\text { kiln, electric heat } \\
\text { storage capacity in the } \\
\text { total capacity }\end{array}$ & $\%$ & \\
\hline
\end{tabular}

(3) The selection of the safety operation index of the station area should reflect the characteristics of the power supply quality of the distribution network, such as the reliability, safety, and power quality of the station area. Including: power dispatch management indicators, power supply reliability indicators, power supply safety indicators, and power quality indicators. The meanings and calculation methods of specific indicators are shown in Table 3: 
Table 3 Calculation method of green development index of electric energy on the side of the station

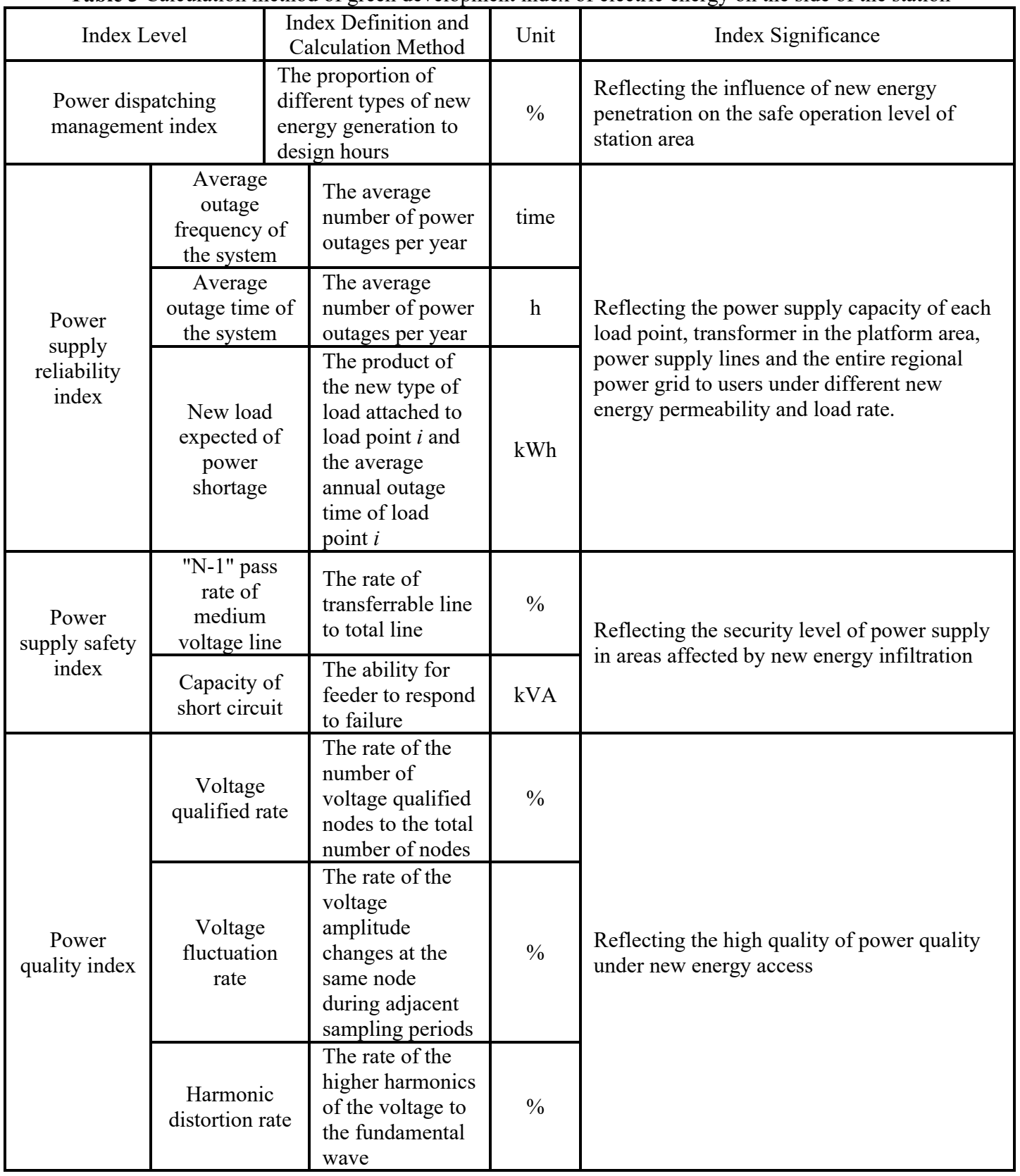

(4) Policy support indicators include the percentage of new energy power generation consumption quotas completed, the percentage of green certificates for

compensation ancillary services, and the percentage of carbon emissions trading. The meanings and calculation methods of specific indicators are shown in Table 4:

Table 4 Calculation method of policy support level index

\begin{tabular}{|c|l|l|c|}
\hline Index Level & \multicolumn{1}{|c|}{$\begin{array}{c}\text { Index Definition and } \\
\text { Calculation Method }\end{array}$} & Unit & $\begin{array}{c}\text { Index } \\
\text { Significance }\end{array}$ \\
\hline $\begin{array}{c}\text { The proportion of new energy consumption quota } \\
\text { completed }\end{array}$ & $\begin{array}{l}\text { The proportion of quota } \\
\text { completion to specified } \\
\text { completion of each } \\
\text { subject }\end{array}$ & $\begin{array}{c}\text { Reflecting the } \\
\text { response degree } \\
\text { of each main } \\
\text { subjective to the } \\
\text { policy }\end{array}$ \\
\hline $\begin{array}{c}\text { The percentage of green certificates for } \\
\text { compensation ancillary services }\end{array}$ & $\begin{array}{l}\text { The proportion of all } \\
\text { kinds of new energy } \\
\text { green certificate trading } \\
\text { quantity and listing } \\
\text { quantity }\end{array}$ & $\%$ & \\
\hline The percentage of carbon emissions trading & $\begin{array}{l}\text { The proportion of carbon } \\
\text { permits traded in total } \\
\text { carbon emissions }\end{array}$ & $\%$ & \\
\hline
\end{tabular}




\section{Construction of Comprehensive Evaluation Model Based on CRITIC- Order Relationship Analysis Method}

\subsection{The objective weight of indicators determined by CRITIC weighting method}

The CRITIC weighting method fully considers the differences and relevance of each indicator. The difference between the indicators is reflected by the contrast intensity. The larger the mean square error of the indicator, the greater the amount of information contained in the indicator. At the same time, the correlation coefficient between the indicators reflects the degree of indicator association. The steps of CRITIC weighting method to determine the objective weight of indicators are as follows:

(1) Index normalization processing

Assuming that there are $\mathrm{m}$ objects to be evaluated and $\mathrm{n}$ evaluation indicators, due to the differences in indicator quantification units, the min-max normalization method is generally used to normalize the indicators before the weight calculation, and the evaluation index matrix $\mathrm{X}$ is constructed:

Positive indicators:

$$
a_{i j}=\left\{\begin{array}{l}
\frac{a_{i j}-\min \left\{a_{i j}\right\}}{\max \left\{a_{i j}\right\}-\min \left\{a_{i j}\right\}}, \max \left\{a_{i j}\right\} \neq \min \left\{a_{i j}\right\} \\
1, \max \left\{a_{i j}\right\}=\min \left\{a_{i j}\right\}
\end{array}\right.
$$

Reverse index:

$$
a_{i j}=\left\{\begin{array}{l}
\frac{\max \left\{a_{i j}\right\}-a_{i j}}{\max \left\{a_{i j}\right\}-\min \left\{a_{i j}\right\}}, \max \left\{a_{i j}\right\} \neq \min \left\{a_{i j}\right\} \\
1, \max \left\{a_{i j}\right\}=\min \left\{a_{i j}\right\}
\end{array}\right.
$$

where: $i=1,2,3 \cdots m ; j=1,2,3 \cdots n$

(2) Evaluation index matrix correlation coefficient calculation

The correlation coefficient is a statistical indicator used to reflect the close degree of correlation between variables. The calculation method is as follows:

$$
r_{i j}=\frac{\sum_{i=1}^{n}\left(a_{i}-\bar{a}\right)\left(b_{i}-\bar{b}\right)}{\sqrt{\sum_{i=1}^{n}\left(a_{i}-\bar{a}\right)^{2} \sum_{i=1}^{n}\left(b_{i}-\bar{b}\right)^{2}}}
$$

where: $-1 \leq r_{i j} \leq 1$, the closer $r_{i j}$ is to 1 , the greater the correlation between the two indexes; the closer $r_{i j}$ is to 0 , the less correlation between the two indexes; $r_{i j}>0$ means that the two indicators are positively correlated; $r_{i j}<0$ means that the two indicators are negatively correlated.

(3) Weight calculation

Using the correlation coefficient matrix of the evaluation index, the contrast intensity $\mathrm{CI}$ between the indexes and the conflicting CT of the indexes were calculated as follows:

$$
\begin{gathered}
C I=\sigma_{j}, j=1,2,3 \cdots n \\
C T=\sum_{i=1}^{n}\left(1-r_{i j}\right)
\end{gathered}
$$

where: ${ }^{\sigma_{j}}$ is the mean square deviation of the index of $\mathrm{j}$.

Based on the contrast strength and correlation coefficient between indicators, the information level of indicators is calculated and the objective weight is given as follows:

$$
\begin{aligned}
& G_{j}=C I \times C T \\
& \omega_{j}^{l}=\frac{G_{j}}{\sum_{i=1}^{n} G_{j}}
\end{aligned}
$$

where: $G_{j}$ is the level of information contained in the index of $\mathrm{j} ; \omega_{j}^{l}$ is the objective weight of the index of $\mathrm{j}$.

\subsection{The subjective weight of index determined by order relation analysis}

The domestic energy supply and consumption structure is in the transition stage, and the relevant policies are still in the process of improvement. Therefore, the index weight of green evaluation of urban distribution network should be improved with the changes of internal and external environment. The order relation analysis method is easy to calculate, reflects the experts' wishes subjectively, and adapts to the green assessment requirements of urban distribution network. The specific steps are as follows:

(1) Determine the order relationship. For a certain evaluation criterion, there is an index order relationship:

$$
A_{1}>A_{2}>\cdots A_{n}
$$

(2) Determine the relative importance of adjacent indicators:

$$
R_{j}=A_{j-1} / A_{j}
$$

(3) Calculation of weight coefficient $\omega_{j}^{2}$ :

$$
\omega_{j}^{2}=\left(1+\sum_{j=2}^{n} \prod_{k=j}^{n} R_{j}\right)^{-1}
$$

The weight of other indicators obtained from $\omega_{j}^{2}$ is as follows:

$$
\omega_{j-1}^{2}=R_{j} \times \omega_{j}^{2}
$$

\subsection{Combination weighting}

According to the objective weight $W^{l}$ and subjective weight $W^{2}$, the comprehensive weight $W=\left[\omega_{1}, \omega_{2}, \omega_{3}, \cdots \omega_{n}\right]$ is calculated by geometric weighted average score as follows: 


$$
\omega_{j}=\frac{\sqrt{\omega_{j}^{l} \omega_{j}^{2}}}{\sum_{j=1}^{n} \sqrt{\omega_{j}^{l} \omega_{j}^{2}}}
$$

\subsection{Calculating the comprehensive evaluation value}

According to the model, the measured data of the index are normalized, and the weighted standard matrix is obtained according to the subjective and objective weight matrix of the index. The comprehensive evaluation value $y_{i}$ is calculated by using the normalized value and the combined weight coefficient:

$$
y_{i}=\sum_{j=1}^{n} \omega_{j} a_{i j}
$$

\section{Analysis of Application Path}

The energy green evaluation index system of urban distribution network constructed in this paper comprehensively reflects the overall energy-saving and emission reduction situation and safe operation situation of the source, grid, and load links in the distribution network, which is a practical application to realize the operation, allocation and adjustment. Specific applications are as follows:

(1) The power green indicators selected in this paper directly reflects the power supply structure on the power supply side, which can provide data reference for grid companies to eliminate high-energy power plants and optimize power supply structure, promote the diversification of energy supply, and improve the utilization of renewable energy.

(2) The consumption-side power green indicators selected in this article analyzes the energy consumption structure of industrial park users, evaluates the impact of various smart terminals, electric vehicles and other equipment access on the green development of the distribution network, strengthen demand-side management for the grid, and promotes power substitute and provides a reference for expanding the new energy consumption market.

(3) The safe operation index of the station area selected in this paper reflects the influence of new energy access on the safe operation of the distribution network through the power dispatch management index and the low-voltage ride-through capability of new energy power generation, and can provide planning and design for green power and random load access to the distribution network. The plan is to adjust the use mode and configuration scale of distributed power generation equipment and energy storage equipment (including electric vehicle charging piles) to achieve green and efficient energy using.

(4) The policy support indicators selected in this article can reflect the degree of policy subsidies for new energy power generation, the level of green power trading and the degree of marketization, which can serve government departments and provide a basis for formulating corresponding energy regulatory policies to promote new energy consumption, increase the enthusiasm of social capital to participate in the incremental power distribution and auxiliary service market.

(5) The green comprehensive evaluation model of urban power distribution network constructed in this paper directly reflects the green development level of the distribution network, promotes the diversification of energy supply, improves the utilization of renewable energy, and releases the adjustable ability of the consumption side. Promoting the clean and efficient supply of urban power from the power supply side, promoting the coordinated and stable development of urban power on the grid side, and guiding the economically friendly consumption of urban power on the load side are an effective method to evaluate the level of green transformation of urban power[7].

\section{5 conclusion}

Based on the background of energy transformation, this paper constructs a comprehensive evaluation index system of urban distribution network electric energy from four dimensions, namely, clean energy supply and environmental protection, low carbon energy consumption, security and stability of courts, and energy policy support level, and makes an in-depth analysis of the relevant factors affecting the green development of urban distribution network. The comprehensive evaluation model based on the analysis of the relationship between the CRITIC and the sequence is established, and the quantitative evaluation of the green development level of electric energy of urban distribution network is realized, and the application approach of the model is put forward, which is helpful to clearly understand the green development level of urban distribution network, guide the transformation and upgrading of urban distribution network, and accelerate the green construction process of urban distribution network.

\section{Acknowledgments}

This research was funded by [State Grid Corporation of China Science and Technology Project, "Research on power Green Index Evaluation System of distribution network based on urban Energy Internet'] [520940190077]

\section{References}

1. Gao Peng. The Evaluation Index System and Comprehensive Evaluation of Operation Safety in Urban Distribution Network[J]. Shandong Industrial Technology, 2019(02): 194.

2. Jiang Jie, Zhou Fulin, Zhong Kai, Yang Ruixuan. Proceedings of the CSU-EPSA[J]. Proceedings of the CSU-EPSA, 2020, 32(08): 47-53. 
3. Lv Zhipeng, Wu Ming, Song Zhenhao, Zhao Ting, Du Gang. Integrated Evaluation Method of Power Quality Based on CRITIC-TOPSIS[J]. Electric Machines and Control, 2020, 24(01): 137-144.

4. Zeng Bo. Integrated Resource Planning and Decision-making Theories of Active Distribution Networks Towards Low-carbon Economy[D]. North China Electric Power University (Beijing), 2014.

5. Sun Yanlong, Kang Chongqing, Chen Songsong, Meng Junxia, Lu chang, Luo Jinshan. Low-carbon Power Grid Index System and Evaluation Method[J]. Automation of Electric Power Systems, 2014, 38(17): 157-162.

6. Xiang Siyang, Cai Zexiang, Liu Ping, Li Licheng. Fuzzy comprehensive evaluation of the low-carbon operation of distribution network based on AHPAnti-Entropy Method[J]. Journal of Electric Power Science and Technology, 2019, 34(04): 69-76.

7. Zeng Bo, Zhang Min, Zhang Jianhua, Dong Jun, Xia $\mathrm{Yu}$, Han Yu. Environmental Effects Evaluation of Urban Distribution Network Planning Based on a Comprehensive Model [J]. General Meeting of the IEEE-Power-and-Energy-Society, 2011. 